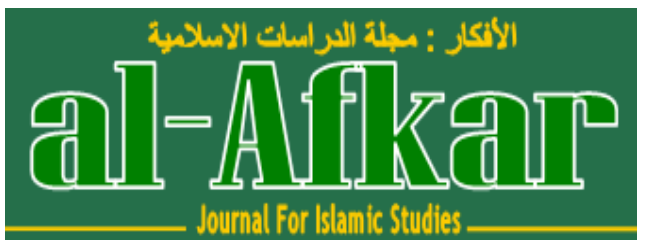

Vol. 2, No. 2, July 2019

P-ISSN : 2614-4883; E-ISSN : 2614-4905

https://al-afkar.com/index.php/Afkar_Journal/issue/view/4

DOI: https://doi.org/10.31943/afkar_journal.v4i1.55

\title{
IS THE TABOO OF FEMALE SEXUALITY THE SOLE REASON FOR THE CONTINUATION OF FEMALE GENITAL MUTILATION IN EGYPT?
}

\author{
Tabi Stew \\ University of Leeds, School of Languages, Cultures and Societies \\ E-Mail: tabistew@gmail.com
}

\begin{tabular}{|c|c|c|}
\hline Received & Revised & Accepted \\
\hline 3 Juny 2019 & 20 Juny 2019 & 1 July 2019 \\
\hline
\end{tabular}

\section{IS THE TABOO OF FEMALE SEXUALITY THE SOLE REASON FOR THE CONTINUATION OF FEMALE GENITAL MUTILATION IN EGYPT?}

\begin{abstract}
As the first conviction of FGM in the U.K. proves, female genital mutilation is a 'harmful cultural practice' that persists across the world. Egypt has one of the highest rates of FGM in the world. Based on a variety of different studies and questionnaires undertaken in doctors' surgeries and hospitals across the country, three clear reasons are given for the continuation of the practice. These are the belief that it is decreed by Islam, that it is a tradition and to preserve young women's chastity as it would reduce their sexual desire. The overarching theme of these justifications is the fear and control of female sexuality, given the teachings of modesty in the Qur'an and the importance of chastity in order to obtain a good marriage in Egyptian society. However, the Qur'an does not condone female genital mutilation or mention it. Additionally, the Qur'an promotes sexual fulfilment and positivity within the confines of marriage for both men and women which directly conflicts with the consequences of FGM. The importance of honour and the preservation of chastity in Egyptian society continues to prevail in modern Egyptian society, and medicalisation legitimises the practice among the educated elite. However, this work hopes to prove that certain interpretations of certain aspects of
\end{abstract}


the Qur'an and the hadith and Sunnah have led to the need to control female sexuality, and these beliefs are intertwined with tradition and result in the continuation of female genital mutilation in Egypt.

Keywords: female sexsuality, female genital mutilation, adn egypt.

\section{Introduction}

Female genital mutilation (also known as FGM, female circumcision and female genital cutting) was an issue I knew little about until a year ago when I was assigned to do a presentation on the topic for my degree. When I began my research, I was shocked to find that Egypt had the sixth-highest rates of prevalence of the practice in the world ${ }^{1}$. This fact particularly affected me as I had lived in Egypt for three years in my childhood. To find that girls as young as I was when I lived there underwent something as violent and scarring as that was an emotional experience, and I found myself trying to learn as much as I could about the practice. This need for information was only amplified by the first-ever conviction of FGM in the UK earlier this year. The issue was brought much closer to home after I discovered that there are around 137,000 victims of FGM in the $\mathrm{UK}^{2}$ and there were approximately 939 reports of calls from young girls in airports fearing that they were going to be sent to another country to undergo the procedure between 2014 and $2018{ }^{3}$. There were many questions racing through my head: why was this happening? Where had it come from? Why were there such high rates of it in certain countries? The most common justifications given for its continuation were that it was traditional, the belief that it was an Islamic obligation and that it would help to preserve a girl's chastity. These justifications appeared to me to be based on the control of female sexuality. Tradition saw this practice as a welcome into womanhood and therefore the first step into the rest of a young girl's life, consisting of marriage and children. The supposed Islamic obligation depicted FGM as a way of pleasing a husband and the belief that it would preserve a girl's chastity reiterated that this was a way of ensuring virginity before a suitable marriage had been made. However, all of the previous, limited literature I had read had not addressed this interpretation, or if it had, it had only briefly spoken on the topic as it is a taboo and illegal practice. This potential desire for control of female sexuality is where the largest gap in the research addressing FGM was, and therefore, was the perfect basis for my dissertation.

There is an existing body of literature which focuses on the medical definitions and implications of female genital mutilation worldwide, all of which discuss the different types, and the immediate and lasting effects the procedure has on the female body. It is widely acknowledged by medical experts that FGM has no

\footnotetext{
${ }^{1}$ Brigitte Gabriel, Rise: In Defense of Judeo-Christian Values and Freedom (Charisma Media, 2018).

2 Sarah M Creighton et al., "Tackling Female Genital Mutilation in the UK" (British Medical Journal Publishing Group, 2019).

${ }^{3}$ Creighton et al.
} 
positive medical ramifications, such as improvement in cleanliness or improvement in fertility as some argue it does. The general consensus in the medical community, outside those countries most affected by FGM, is that the procedure is harmful to women's health and they have built an extensive body of information on the debilitating effects that are left in its wake. delves into the issues that are faced in sexual function ${ }^{4}$, but also those that occur almost immediately in the aftermath of the procedure and the effects that impact the process of childbirth and menstruation. This work is particularly useful in bringing to light the lasting implications of female genital mutilation, and also in focusing this issue in Egyptian society. was equally beneficial for emphasising the extent of the practice in Egypt and the cultural ramifications women suffer if they have not been subjected to the procedure ${ }^{5}$.

However, literature that specifically deals with female genital mutilation in any other terms than the medical implications is limited. Given the official condemnation of FGM, most countries denounce the practice altogether and generally attempt to keep any evidence of the practice under wraps. There are very few countries and governments which are genuinely perpetuating the practice, and even the official stance of the Egyptian government that of denunciation. It has generally been accepted that Egypt and Sudan are the only two predominantly Muslim countries in which FGM exists, but Mona ${ }^{6}$ proves that it is not the case. Her research into various studies across the region confirms that there have been traces of female genital mutilation in many more countries. While the instances of incidents are minimal, Eltahawy's work brings to light a fact that even UNICEF ignores, which makes her book beneficial in suggesting that this practice could have been adopted by certain schools and sects in Islam. 'Dissecting the claims of legitimisation for the ritual of female circumcision or female genital mutilation (FGM)' (2014) by Muhammad Munir is helpful in assessing the legitimacy of the religious claims made by these schools and sects and members of the religious elite, bringing to light the justifications given and analysing their credibility.

As a result of the invasive and personal nature of this topic, there is very little other literature that directly refers to female genital mutilation in Egypt and attitudes towards it. However, the importance of honour of girls and the preservation of virginity is particularly obvious in Egyptian society. There are few who write as eloquently on this subject as. ${ }^{7}$ This work has been invaluable in bringing to light the full extent of the importance of chastity in a young girl's life. Her personal experience growing up in rural Egypt, as well as her involvement in the medical community as a nurse, provides valuable insight into the common beliefs

\footnotetext{
${ }^{4}$ Manal Ibrahim Hanafi Mahmoud, "Effect of Female Genital Mutilation on Female Sexual Function, Alexandria, Egypt," Alexandria Journal of Medicine 52, no. 1 (2016): 55-59.

${ }^{5}$ John Tochukwu Okwubanego, "Female Circumcision and the Girl Child in Africa and the Middle East: The Eyes of the World Are Blind to the Conquered," in Int'l L., vol. 33 (HeinOnline, 1999), 159.

${ }^{6}$ Mona Eltahawy, Headscarves and Hymens: Why the Middle East Needs a Sexual Revolution (Farrar, Straus and Giroux, 2015).

${ }^{7}$ Nawal El Saadawi and Nawāl Sa'dāwī, The Hidden Face of Eve: Women in the Arab World (Zed Books, 2007).
} 
and practices among the Egyptian population. In addition to this, she is one of the very few I have found who have directly written about the correlation between the control of female sexuality and female genital mutilation. Her first-hand account of her own circumcision and the accounts of other women that she gives have added to the scarce accounts of the procedure and, therefore, this has been one of the most valuable pieces of literature in my work.

It is of the utmost importance in my work to ensure that this is not an unprecedented attack on what has been deemed a 'cultural' practice. As a result, it was essential that accounts of women who had undergone the procedure and write about their personal experiences with it were incorporated. However, again, the literature on experiences with this procedure is limited given that it is a particularly violent moment in a young girl's life and some do not wish to speak about it, that it is about an extremely personal body part, and that it is illegal in Egypt. 'Khul Khaal: Five Egyptian women tell their stories' ${ }^{8}$ was critical in ensuring that the voices of Egyptian women were represented in this work. Including sincere and genuine accounts and experiences of these five women from across Egypt and from different religious backgrounds is essential in legitimising the justifications for the continuation that have been discussed in this work. The varied backgrounds of these stories cement this in Egyptian society and prove that it is not necessarily an Islamic issue. The only problem that arises with this book is that it was published in 1984 and the accounts, therefore, are not recent. Despite it being written in living memory, it is said to be not representative of girls' experiences now, as it predates Egyptian medicalisation of FGM. However, these have been the experiences of women for the last thousands of years and, while it is not the reality for many in urban areas, those who live in rural Upper Egypt still have encounters similar to these.

While the mentioned literature has been essential in my research, there are still large gaps apparent. It is undeniable that female genital mutilation is harmful to women's health, that it is a problem across the Muslim world and beyond and that there is an issue with the importance of virginity and virtue in Egyptian society. However, there is no literature that brings all of these points together and directly relates them all to FGM and female sexuality. In addition to this, there is also very little available which assesses the validity of the Islamic justifications for female genital mutilation based on the theory of Islamic law. All of this is important in building a valid argument for the practice to be ended. To bring all aspects of the arguments for continuation for FGM in Egypt together and assess and analyse them is what I wanted to look into for this piece of work.

There are several issues which arise when addressing female genital mutilation. Firstly, in my case, there is the problem of positionality. FGM has long been viewed as a traditional, cultural practice and is, for the most part, practised in Africa and the Middle East. Given the horrific attacks on many cultural practices

${ }^{8}$ Nayra Atiya, Khul-Khaal, Five Egyptian Women Tell Their Stories (Syracuse University Press, 1982). 
across the African continent throughout the Colonial era, it is entirely understandable that this work could also be viewed as yet another attempt to take more away from the traditions of many and feed into Islamophobia. As I personally have no cultural, traditional or religious affiliation to FGM, I have tried not to allow my opinions on the act merge into my work, but rather let the research speak for itself. This topic is emotional, to say the least, but it has to be approached rationally. In order to do this, I have included the thoughts and opinions of survivors who have experienced this procedure first-hand. The intention is to demonstrate the pain experienced in the procedure as described by the real experiences of those who have undergone this practice and so prove that FGM is harmful. Trying to put an end to this practice and raising awareness for the victims is far too important to be undermined by the fact that I am white, atheist and British, and while I am all too aware of the implications this has on attitudes to this work, my main focus in on the millions of young girls who have been scarred, mutilated and even died as a result of a 'cultural' practice.

Another problem I have encountered in writing this is the fact that female genital mutilation has been labelled a cultural practice. By describing it as 'cultural' or 'traditional' this procedure becomes almost untouchable. In this label, FGM becomes separate from the West, despite the fact that it clearly isn't, considering our own experience with it, and introduces the notion of interference into a history and culture that is not ours. Had this ancient practice not been adopted or intertwined with history, culture and religion, it would be known today as what it truly is: child abuse. By naming it 'cultural', FGM is justified and put on a pedestal. It has the same validation as 'honour killings', which, regardless of the numerous campaigns and attempts to bring it to an end, continue to affect female, and increasingly male, populations across the world. What is considered domestic violence in the UK is given the title of 'honour killings' elsewhere to create a barrier of separation and emphasise the notion of the 'other'. While it is agreed that FGM is a 'harmful cultural practice', it remains a 'cultural practice' and one of the first things that needs to be addressed in order to begin the process of ending this abuse is the removal of this label.

One of the greatest challenges in this topic is the issue of the term 'female circumcision'. This label has resulted in the belief that female genital mutilation is comparable with male circumcision, which it is not for several reasons ${ }^{9}$., a luxury that is not afforded to most girls. Additionally, there has been evidence to suggest that male circumcision has reduced the risk of HIV by 6o per cent (WHO, 2019), while there has been no evidence of the medical benefits of FGM. With these key differences, along with a whole host of others, in the conditions under which each procedure is performed and the benefits, or lack thereof, of the operation, the two procedures cannot be compared.

\footnotetext{
${ }^{9}$ Isabell Utz-Billing and Heribert Kentenich, "Female Genital Mutilation: An Injury, Physical and Mental Harm," Journal of Psychosomatic Obstetrics \& Gynecology 29, no. 4 (2008): 225-29.
} 
Tabi Stew

Is the Taboo the Female Sexuality......

\section{Methodology}

Due to the sensitive nature of this topic, research took a long time. There was a plethora of material on medical definitions and different types of female genital mutilation but finding anything beyond this point proved to be difficult. The majority of sources I have used have been secondary sources, including journals, studies and some accounts of survivors. As a result, the first chapter of this work is data-based, considering rates of FGM across the world and in Egypt specifically. However, the remainder of this dissertation is based on empirical evidence. While I have not been able to gain any primary sources, I have managed to find second-hand accounts of survivors, which have helped to validate my argument.

In regard to theory, I have focused on theories in Islamic law as well as Muslim feminist theories in order to legitimise my argument. Additionally, this piece of work is entirely based on gender theory, as this is a gender issue.

\section{Result and Discussion}

\section{The Essence of FGM?}

Female genital mutilation has been prevalent in many societies across the world. In this chapter, the definition of this custom and the consequences that come as a result of it will be explored to describe exactly what this practice entails. It is important to then delve into the historic details and attempt to understand where its origins are and how it has progressed through the centuries, tracking its course in different countries. Due to the focus on Egypt in this work, the prevalence of mutilation in Egypt will be discussed, assessing attempts made by the government to control it and the strength and belief in its continuation in the country. This is important to explain before addressing the justifications given for its continuation and the question of why the practice is fought for so fiercely in Egyptian society.

The medical definition

Female genital mutilation is a violent act against young girls, which normally takes place between the ages of four and eight years old (Toubia, 200o), but can be any time before puberty (Mahmoud, 2016). The World Health Organisation (WHO) defines the practice as "all procedures that involve partial or total removal of the external female genitalia, or other injury to the female genital organs for nonmedical reasons" (Mahmoud, 2016). There are four registered types of FGM: type one (or Sunna circumcision) is the removal of the clitoris and clitoral hood; type two (or clitoridectomy) is the removal of the clitoris and labia minora; type three (or Pharaonic circumcision) is the removal of all or part of the labia minora and majora, and usually the clitoris, the wound is sutured to allow the passing of urine and menstrual blood and is reopened for sexual intercourse and childbirth; and the final type is designated for miscellaneous procedures at the external genitalia, such as the 
cauterisation of the clitoris and cutting into the vagina in order to widen it (Mahmoud, 2016). Recorded rates of FGM across the world are varied, with WHO reporting that 140 million women and girls across the world have undergone the procedure (Mahmoud, 2016), whereas UNICEF contests this figure, estimating that at least 200 million women and girls alive today have been subjected to it (Lesclingand, 2016). It is impossible to get an exact figure due to the fact that it is such a taboo topic, even among societies where it is widespread. Without the exact numbers, it is extremely difficult to know just how many women and young girls have been subjected to this custom, but it is fair to say that the damage is extensive.

What these millions of women and girls are subjected to is not simply the cutting, but also the multiple effects, both physical and psychological, left in its wake. Multiple sources have recorded that there is no health benefit whatsoever (Okwubanego, 1999, p. 163). The most common immediate medical consequences are infections, abscesses and clitoral cysts (Dalal, et al., 2010), and the long-term consequences include chronic pain, difficult labour and even infertility (Mahmoud, 2016). All of these side effects result in intense pain and a lifetime of sexual and reproductive issues (Lesclingand, 2016) in the name of preventing young girls from having sex before marriage (Okwubanego, 1999, p.163). In a study released in 2016, it was found that 73.9 per cent of women questioned had more painful menses as a result of the procedure, 42.3 per cent experienced irregular menses, 43.4 per cent had obstructed labour and 27.6 per cent suffered postpartum haemorrhage (Mahmoud, 2016). These statistics are much higher than those of the average women's menstrual cycle, which suggest that 14 per cent of women suffer from painful, irregular or heavy periods (Holland, 2018). Some studies have even suggested that women who have undergone this procedure have been unable to orgasm as a result (Okwubanego, 1999, p. 171) This is unsurprising given that the tip of the clitoris has a dense supply of around 8,00o nerve endings (Madsen, 2015) and is the primary specialised female sexual organ (Toubia, 200o, p. 419). Removing the specific organ designated to female sexual pleasure takes power away from women and reinforces the belief that sex is shameful, and especially that female sexual desire and enjoyment is wrong. The combination of the procedure of cutting, the effects that those who have suffered from this practice continue to suffer throughout the rest of their lives, and the familial pressure of honour and chastity truly depict the extent of shame in female sexuality intrinsic in societies that have practised female genital mutilation.

\section{Its traces through history}

The issue that faces the West is that FGM appears to be a practice of the 'other' and is viewed as an African problem. However, the true origins of the practice are unknown and traces of it have been found all over the world. It is widespread across Africa (Daly, 1991, p. 161), but there have also been reports of it in Peru, Aboriginal Australia, India, South America (Daly, 1991, p. 162), Europe and America (J., Ayonrinde, \& Maingay, 2010, p. 161). In ancient Rome, slaves had metal rings passed through the labia minora and women in medieval England wore chastity belts 
(J., Ayonrinde, \& Maingay, 2010, p. 162). All of this was used in a similar fashion to female genital mutilation today. Clitoridectomies were performed in England fairly regularly in $19^{\text {th }}$ century Britain as a cure or management of epilepsy, sterility, and masturbation (J., Ayonrinde, \& Maingay, 2010, p. 162). Additionally, they were used as a way of treating 'mental illness', such as hysteria, and behaviour that was thought to be unfeminine and a threat to marriage, such as a lack of desire to engage in sexual relations with her husband or even answering back (King, 2015). It was not until 1866 when the Obstetrical Society challenged it that it fell out of practice (J., Ayonrinde, \& Maingay, 2010, p. 162). Mutilation was also common in America, justified by Dr A. J. Bloch, who wrote 'Sexual perversion in the female' in 1894 (J., Ayonrinde, \& Maingay, 2010, p. 162). He claimed that female masturbation was "moral leprosy" and could only be cured by removing the clitoris (J., Ayonrinde, \& Maingay, 2010, p. 162). One woman was subjected to clitoridectomy after surviving rape in the early twentieth century in the United States in order to protect her from becoming sexually out of control after her ordeal (Eltahawy, 2015, p. 137). This same issue of the depiction of female sexuality as immoral and undisciplined is recurrent throughout world history and cannot be simply blamed on one religion or culture, as it has been prevalent in all. It is only because the West has distanced itself from it that the fact that Europe and the West are also guilty of female genital mutilation has been forgotten. Modern cases of FGM in Europe and the US have been isolated, usually performed as misguided experimental psychiatric procedures and have never been performed by families and communities on their young daughters as routine.

Benoit Groult claims that both the mummies of Cleopatra and Nefertiti lack clitorises (Daly, 1991, p. 162) and while this is a highly controversial claim, the first reference to excision was recorded on papyrus dating back to the second century BCE in Egypt (Lesclingand, 2016) which suggests that it was present in Ancient Egyptian society. Daly has also referred to many mummies that were discovered having been subjected to the Pharaonic method of mutilation (Daly, 1991, p. 162) and it appears that it might have been a common part of female life among royalty (Daly, 1991, p. 162). This has been widely discussed, with multiple other Egyptologists claiming that there is no evidence to support this (Lorenzi, 2012). The first literary mention of the custom was by the Greek geographer Strabo in 25 BCE, when he recorded, "This is one of the customs most zealously pursued by [the Egyptians]: to raise every child that is born and to circumcise the males and excise the females" (Knight, 2001, p. 318). Strabo portrays the practice as being distinctively Egyptian (Knight, 2001, p. 318), but this may tie in with the 'fetishising of the colonised' that took place in the Graeco-Roman era of Egyptian history (Knight, 2001, p. 319). Additionally, mutilation has been linked to the slave trade, and may have been practised on female slaves in Ancient Rome as a form of control (Lesclingand, 2016) It is possible that it was due to both the Romans and the Greeks that the practice could have shifted from a religious rite to a medical procedure (Knight, 2001, p. 329). While it is not an exclusively African problem and its origins are unclear, it is clear that it has existed in Egyptian society since the second century BCE. 
Tabi Stew

Is the Taboo the Female Sexuality......

\section{Egypt}

As with the rest of the world, it is difficult to obtain accurate figures of rates of female genital mutilation in Egypt. Types I and II are predominantly practised here (Langer, 2018). It has commonly been reported that 97 per cent of Egyptian women have been subjected to it (Dalal, et al., 2010), but a recent UNICEF study found that 87 per cent of Egyptian women between the ages of 15 and 40 have undergone the procedure (Langer, 2018). This figure does, however, discount women over 40, who are more likely to have undergone the procedure. These numbers are particularly high considering the practice was banned in Egypt entirely in 2008 (Alkhalaileh, et al., 2018). The death of a ten-year-old girl at the hands of a barber, who was performing the procedure on her in 1996 (Okwubanego, 1999, p. 169), was covered in great detail by CNN (Okwubanego, 1999, p. 169) and brought the issue to the forefront of world news, putting pressure on the Egyptian government to put an end to this brutal operation. Although a ban was put in place that year, accounts from 1999 stated that seven out of ten girls were circumcised, with around 4,000 being cut daily (Okwubanego, 1999. p. 160). The common belief is that many young girls are subjected to the same conditions as the ten-year-old in 1996 or worse. In many cases, the procedure is performed by a senior female member of the family, or by someone in the neighbourhood, such as a daya, without anaesthesia or any qualified professional present (Dalal, et al., 2010). Additionally, some of the tools that have been recorded as being used are sharp stone, broken glass, an iron piece, a tin lid, razor blades, knives, scissors or needles, none of which are normally sterilised before or after (Dalal, et al., 2010). One of the potentially more disturbing factors about Egypt as a case study is that many medical professionals also perform the operation (Rasheed, et al., 2011). It has been reported in studies that the vast majority of incidences of the practice were performed by general practitioners (Rasheed, et al., 2011) while 48.9 per cent were performed by dayas or midwives (Mahmoud, 2016). The process of medicalisation began in 1994, when, in an attempt to lower the number of deaths as a result of the procedure, the Minister of Health decreed that it would only be practised in licensed hospitals and by physicians (El-Gibaly, et al., 2002). This was repealed the following year due to local and international cries of condemnation (El-Gibaly, et al., 2002). However, the fact remains that mutilation continues to be carried out by medical professionals who support its continuation. A survey carried out between 2008 and 2010 in Soha and Qena University Hospitals in Upper Egypt revealed that 88.2 per cent of nurses, 34.3 per cent of young physicians and 14.9 per cent of senior physicians approved of the practice (Rasheed, et al., 2011). With this kind of support from the medical community, it is unsurprising that rates of female genital mutilation have remained consistently high.

In addition to the support of the medical community, there is widespread support for the continuation of female genital mutilation by the general population. In the 1995 Egypt Demographic and Health Survey, 88 per cent of the mothers surveyed said that they would circumcise their daughters (El-Gibaly, et al., 2002). A 
study done less than ten years later showed that the girls of this generation were 6 to 10 per cent less likely to undergo the treatment than their mothers (El-Gibaly, et al., 2002), and reported that 14 per cent of those girls already circumcised thought the practice was unnecessary and 28 per cent were ambivalent towards it (El-Gibaly, et al., 2002). This shift in attitudes is a great improvement for such a short time period, but the fact remains that many view the procedure as a deeply rooted tradition in Egyptian society and movements to stop it have been accused of cultural imperialism and being invasive in African and Middle Eastern cultural ideas (Okwubanego, 1999, p. 173). Female genital mutilation appears to be ingrained in Egyptian culture and society and without education of both medical professionals and the public of the risks that it entails, it shows no significant signs of stopping.

Female genital mutilation is a practice that has been recognised and used all over the world, by different cultures, religions, and races throughout history. The procedure itself in all four different types makes sexual enjoyment difficult and all involve the removal of perfectly healthy tissue, which does not have any health benefits, and also leaves irreparable physical and psychological damage. The continuation of the practice is fiercely fought for by both members of society and of the medical profession, making it even harder to put a stop to. In the following chapters, the reasons for the continuation of this practice will be explored and explained.

\section{Is Islam a viable justification?}

Islam has been one of the most commonly used justifications for the continuation of female genital mutilation in the Muslim countries in which it is practised. However, it has repeatedly been mentioned that there is no basis for FGM in Islam, and only certain Islamic schools actually practice it, while many others are not only unaware of it, but are disgusted and shocked to hear of it. This chapter will address where FGM has been discovered, the arguments that are used to justify it in the hadith and the Qur'an, and the discourse between this practice and the sex-positivity of the Qur'an.

Where else does it happen?

There are many schools which denounce the practice as completely unIslamic and say that it is prohibited (Munir, 2014). While it is commonly accepted that FGM does not occur in Saudi Arabia, Iraq, the Gulf States, Kuwait, Algeria and Pakistan (Toubia, 200o, p.422), this belief has been recently debunked. According to WADI, an Iraqi German NGO, clinical research in the possible connection between female sexual dysfunction and FGM conducted in 2007 to 2008 in Saudi Arabia found that of 260 women interviewed in a Jeddah clinic, half of them had been cut (Eltahawy, 2015, p. 134). It was thought that some of the participants were Saudi Arabian and others were migrant women, which could explain why this number was so high, but in a study conducted in Kuwait and Saudi Arabia, 38 per cent of 4,80o 
pregnant women questioned had undergone FGM (Eltahawy, 2015, p. 134). Additionally, anecdotal evidence suggests that it occurs in the Eastern Province of Saudi Arabia and that it was also practised earlier in the 20 th $^{\text {th }}$ Century among some Bedouin communities (Doumato, 2010, p. 24). Saudi Arabia and Kuwait are not the only exceptions, however, as research by students at Dubai Women's College found that it was practised in the United Arab Emirates (Eltahawy, 2015, p. 135). Their research revealed that in a 2002 survey of 200 students of both sexes, 34 per cent of females said that they had undergone the procedure (Eltahawy, 2015, p. 135). On top of this, it has recently emerged that it is present in Oman, Indonesia, Malaysia, parts of Pakistan and India, and the Kurdish areas of northern Iraq (Eltahawy, 2015, p. 135). It is not commonly thought that this practice is prevalent or even exists in these areas as the subject is so taboo and commonly silenced, and even UNICEF does not recognise any of these as countries in which FGM takes place (Eltahawy, 2015, p. 135). With this evidence of the prevalence of FGM in so many predominantly Muslim areas, it appears as though it is a practice that has been adopted by Islam.

Is there a basis in the religious texts?

It is important here to reiterate that female genital mutilation is not prescribed by any religion, even if religion is used to justify it. It is repeated time and again that FGM predated Islam in Africa (Toubia, 2000, p. 421) and is not directly mentioned in the Qur'an, hadith or Sunnah (Eltahawy, 2015, p. 127). There is a general belief that, over time, this practice was adopted by some Muslims in countries where it was already prevalent and eventually it was thought to be required by Islam (Toubia, 2000, p. 422). However, this is mistaken. The Prophet Mohammed is said to have opposed to the custom as he thought it harmful to the sexual health of women, following the advice given to him by a woman named $\mathrm{Om}$ Attiah (El Saadawi, 2015, p. 82). She told him that only a small amount of the clitoris should be cut as this would make the face of the woman 'bright and happy' (El Saadawi, 2015, p. 82). It is claimed that he told his listeners to circumcise, but not to destroy or mutilate, as not destroying the clitoris would be better for the man and, again, it is mentioned that this would make the woman's face glow (Toubia, 2000, p. 422). However, even this supposed speech by the Prophet does not call for female circumcision as an essential act for Muslims and it specifically says not to mutilate. Dr Ali Juma'a, a former Egyptian Mufti, made the point that the Prophet did not circumcise any of his four daughters, which begs the question why any other Muslim would be required to do it (Munir, 2014). Additionally, there is no evidence to suggest that Islam as a religion has adopted the practice (Munir, 2014). While some schools do perform FGM, in some areas of the Muslim world it is heavily frowned upon and many can hardly believe that it happens at all. There is no clear justification that it is an Islamic practice and while many have argued that it is, it is clear that it has not been adopted by the majority of the Muslim world to have been decreed as such by the Prophet, and there is nothing to suggest that it is a necessity 
in the Qur'an, any of the hadith or the Sunnah. So, what is the basis and argument of those who do practice it?

What are the main textual arguments?

There are many arguments given in the justification for female genital mutilation, ranging from interpretations of hadith, the use of qiyas and several fatwas. One of the hadiths that are commonly referred to is that of Om Attiah, mentioned here earlier. However, this has been condemned to be a weak (da'ef) hadith as one of its narrators is unknown. It has been suggested that the same narrator might be Muhammad bin Sa'eed bin Hassan who was crucified for fabricating hadith (Munir, 2014). Any hadith that is found to be weak cannot be followed and is disregarded. This seems to be a recurring issue in several other hadiths that have been used for justification. Another issue that appears to be common among certain hadith that appear to permit female genital mutilation is that it is labelled as 'makrama' (Munir, 2014). The general consensus is that makrama means that an act is 'noble' but is by no means necessary, which ultimately means that FGM is not necessitated by any hadith that labels it makrama. The principle of qiyas has also been brought into the process of justification. There is a hadith which states that there are five things that are part of human nature: circumcision, removal of hair beneath the navel, removal of armpit hair, cutting of nails and trimming of a moustache (Munir, 2014). This is specific to men as male circumcision is prescribed by Islam and this is where qiyas comes in to play. It is argued that male circumcision could be considered as the original case and through analogical inference, it could be deduced that female circumcision is equally necessary (Munir, 2014). This argument has been punctured by the fact that there is no common cause between the two cases as they are very different from each other (Munir, 2014). It is thought that male circumcision holds health benefits for men, whereas female circumcision is mutilation (Munir, 2014) and the severity of both is entirely different. However, it is prohibited in Islam to disfigure or change God's creation or cut off any part of the human body (Munir, 2014), which condemns both female genital mutilation and male circumcision. Despite this, advocates from the Shafi'i school are fervent in the belief that circumcision is obligatory for both men and women based on the two opinions of Imam Ahmad bin Hanbal (Munir, 2014). In the first, he stated that it was a source of respect and labelled it 'mustahab', but later declared it obligatory (Munir, 2014). This supposed declaration makes it difficult to prevent the schools that preach the teachings of Imam Hanbal from practising FGM. In addition to the conflict over the hadith, multiple fatwas have been issued on the subject, several of which stand very firmly in favour of the practice (Munir, 2014). One of these is the prominent Saudi Salafi cleric, Shaykh Muhammad al-Munajjid, who denied that female circumcision was an inherited custom, and stated that it was prescribed in Islam (Munir, 2014). While this fatwa arguably is not surprising coming from one so conservative, there are also several fatwas issued by Shaykh Jaad al-Haq who was a former Shaykh of al-Azhar, which is generally seen as a liberal organisation that 
denounced the practice as not being Islamic in 2006 (Alkhalaileh, et al., 2018). He considers female circumcision as a part of the fitrah of Islam and claimed that if anyone in Islam refused to practice either male or female circumcision, the head of the Muslim state can declare war on them (Munir, 2014). This is not the opinion of many others in the religious elite, or the vast majority in al-Azhar today, and many other prominent Muslim religious scholars in Egypt are calling for the practice to be ended (Alkhalalileh, et al., 2018). It is clear that there is no evidence of the necessity for female genital mutilation in the Qur'an, and all hadiths used to argue for it are weak and therefore cannot be used in justification. Additionally, the act of removing entirely healthy body parts goes against a core principle of Islam which ultimately proves that the practice is un-Islamic.

\section{Sexuality in the Qur'an}

It has long been thought in the West that Islam is a very modest and conservative religion with similar attitudes towards sex as Christianity. However, sex within the confines of marriage is of the utmost importance, with emphasis placed on the sexual satisfaction of both parties (Toubia, 2000, p. 422). Unlike Christianity, Islam acknowledges women's sexuality and accentuates the need for female sexual fulfilment (Toubia, 2000, p. 422), proven by passages in the Qur'an and hadith (Eltahawy, 2015, p. 127). Sexual pleasure is also portrayed as one of the attractions of life and the reward for those who are accepted into Paradise after death (El Saadawi, 2015, p. 276). The Prophet discussed sex and sexual satisfaction for both husband and wife and the Wasa'il hadith even states that omitting foreplay is cruel (Eltahawy, 2015, p. 127 (Wasa'il vil. 14, p. 40)). It is clear that the Qur'an, the hadith and the Prophet all advocate for sexual enjoyment within the confines of marriage, which is what makes the practice of female genital mutilation in Islam more confusing. Why would such a sex-positive religion adopt an act which takes this right to sexual fulfilment away from women?

Interpretations of the Qur'an have introduced shame into the equation. Take, for example, the Sunnah of Yusuf, in which the Prophet Yusuf is seduced by the wife (named Zulaykha) of the man he works for, but they are caught before he succumbed to her temptation (Lamrabet, 2018, p. 45). Upon discovering the two, the husband says 'inna kaydakunna 'azim', which is translated to 'your female cunning is truly formidable' (Yusuf 12:29). This phrase has been used in condemnation of all women and has led to the belief that all women are illicit temptresses and that female sexuality is one of the most powerful and dangerous forces on earth, also known as fitna (Lamrabet, 2018. p. 48). However, it has been argued that, rather than this being a condemnation of all women and their sexual desire, it instead is a declaration of disappointment by her husband at this act of betrayal (Lamrabet, 2018). There is no assertion to her being evil in the following passages in the Qur'an, and once she confesses to trying to seduce Yusuf, she is forgiven and, rather than being a symbol of temptation, she becomes a symbol of the human soul or nafs, struggling with temptation into evil but attempting to remain pure (Lamrabet, 
2018, p. 56). Ultimately, a literal interpretation of this Sunnah could result in the belief that all women are inherently evil, and their sexuality must be repressed, but literal interpretations would suggest that it is an individual issue, which she dealt with through an admission of guilt. Unfortunately, many have decided on the interpretation of evil, resulting in theories such as that of Imam Ghazali, which states that women are destructive, and their sexuality is synonymous with the Satanic (Mernissi, 2011, p. 43). Ghazalian theory suggests that the necessity for female sexual fulfilment in marriage is due to the fact that if they are not satisfied by their husbands, they will stray, which will ultimately result in the breakdown of society (Mernissi, 2011, p. 55). As a result, female sexuality must be treated with caution, as it is a threat to the Muslim social structure, by threatening to distract men from their social and religious duties (Mernissi, 2011, p. 56). While Islam recognises both male and female sexuality, it is only female sexuality that is constrained (El Saadawi, 2015, p. 282), and the belief that FGM moderates female sexuality (El-Gibaly, et al., 2002), is arguably why female genital mutilation has been justified in certain schools. However, this practice does exactly the opposite of this justification. It has been proven time and again that it does not smother or stop female desire, but instead removes a woman's ability to achieve sexual fulfilment as it is the removal of the sole organ designated to female sexual pleasure. As a result, this practice cannot be justified by Islam.

Islam does not, therefore, seem to condone or justify female genital mutilation. While traces of FGM have been found across the Islamic world, it is by no means a universally Islamic practice. Although some schools have attempted to justify it through the use of hadith, it is clear that all of the examples given are unreliable and weak, and therefore cannot be used. Finally, the sex positivity of the Qur'an and its teachings about marriage do not align with the practice. If sexual fulfilment of both husband and wife are essential in Islam, then female genital mutilation cannot be prescribed by Islam, as it takes away the ability of women to be sexually satisfied and fulfilled. Therefore, Islam is not a viable justification for the continuation of female genital mutilation.

\section{The Egyptian Case}

As previously discussed, Egypt has almost incomprehensibly high rates of female genital mutilation, and while there is evidence of FGM in other predominantly Muslim countries, there are few others which have as many reported incidents as Egypt. This chapter will delve into the social and cultural issues which may have contributed to the continuation of this practice, such as the prevalence of honour in Egyptian society and the introduction of the medicalisation of the procedure. At this point, and in the context of the rest of this chapter, it is important to bring in the experiences of Egyptian women who have been subjected to female genital 
mutilation, so accounts of these experiences will also be addressed in order to focus this discussion in Egyptian society.

\section{Honour (and the hymen)}

Honour is of the utmost importance in the life of an Egyptian girl. It is thought that the hymen is the ultimate proof of honour and virtue, as an unbroken hymen implies virginity. Parts of Western societies also believe this, but the importance of chastity is incomparable to that of Egyptian and many other Muslim societies. In Egyptian culture, it is thought that a girl cannot make a 'good' marriage without the preservation of the hymen and the removal of the clitoris. According to a study released in 2018, women make up roughly 25 per cent of the Egyptian labour force, and, as a result, rely on marriage for financial stability (Alkhalaileh, et al., 2018). In The Hidden Face of Eve, Nawal el Saadawi recounts a story of a young girl who was brought to her who had fallen in a bath of boiling water and her mother was wailing, asking, not if she was alive, but whether her hymen was still intact (el Saadawi, 2015, p. 54). This belief is prevalent in Egyptian society, with 'virginity tests' occurring across the country on wedding nights. Many women recall their wedding nights beginning by being pinned down by family members, legs held apart, and a nurse, daya or other family member forcing a finger covered with a white cloth inside them to test whether blood came out as the hymen was broken (Atiya, 1984, p. 14) as proof of virginity. One woman stated that 'a girl's honour is worth the world. Her happiness is built on it. It's destroyed without it and can never be repaired.' (Atiya, 1984, p. 14). The fear of being rejected for having a broken hymen has even led some women to reconstructive surgery (Eltahawy, 2015, p. 111). While these 'virginity tests' have fallen out of mainstream practice in the majority of Egypt, women who were arrested during the Arab Spring and the Egyptian uprising were subjected to this as a form of torture by the police, and threatened with prostitution charges, making them, by all accounts, unmarriageable (Eltahawy, 2015, p. 99). In addition to this, Elhamy Agina, a member of the Egyptian parliament suggested the introduction of virginity tests for incoming university students in September 2016 (Langer, 2018). One of the greatest arguments against the use of the hymen as a signpost of virginity is that all women are physiologically different. Some hymens are so thin that they could break with riding a bicycle or a horse, while others are very thick and may take excessive force to break, and any girl with either of these aforementioned types may not bleed as a result of these tests (el Saadawi, 2015, p. 53). It is thought that more than 30 per cent of girls do not bleed during their first sexual act (El Saadawi, 2015, p. 57). However, the common belief is that the only reason a girl does not bleed is that she has already had sex, and therefore brings shame to her family. This perceived shame does sometimes lead to honour killings (El Saadawi, 2015, p. 55). In an attempt to prevent this, dayas have been known to use tricks to ensure that there is blood visible on the cloth, including placing a small bag of chicken's blood at the opening of the vagina as the test is happening (El Saadawi, 2015, p. 63), or even using their nails to cut through the wall of the vagina 
Tabi Stew

Is the Taboo the Female Sexuality......

(El Saadawi, 2015, p. 6o). It is clear that a girl in Egypt must uphold the family honour through her virtue and chastity, but the only way this can be proven is through the torture of what is, in reality, rape. While the hymen is in no way an indication of virginity, these young girls are subjected to numerous violations in the name of honour, which proves its importance in Egyptian society.

The necessity for the preservation of the hymen goes hand in hand with female genital mutilation in Egyptian society. A girl must be delivered to her new husband with both of these qualities for the wedding night (Eltahawy, 2015, pg. 115). Mona Eltahawy in her book 'Headscarves and Hymens: why the Middle East needs a sexual revolution' recounts a story of a young woman who was returned to her family home on the night of her wedding with a note from her new husband, on which he wrote 'If you want your daughter to be married, you know what you need to do'. She had not yet been circumcised, but a daya was called immediately, and the procedure took place that night (Eltahawy, 2015, p.119). The honour of the family is held in such high importance that women's childhood experiences are completely disregarded in place of intrinsic abuse.

\section{Legitimisation through medicalisation}

Egypt is such an extraordinary case because of the medicalisation of female genital mutilation. In 1959, the Minister of Health banned medical practitioners from conducting the practice without clear medical indication or necessity, but in 1994, a decree was passed by the Minister of Health at the time which allowed physicians to perform the procedure (El-Gibaly, et al., 2002). While this was repealed the following year, the medical community have continued to support and perform the procedure. The 1994 decree was intended as a hopeful step towards the abandonment of FGM by attempting to take the power out of the hands of the dayas and other nonmedical and inexperienced individuals (Al-Dawla, 2000, p. 430). It instead became accepted and adopted by the medical community (El-Gibaly, et al., 2002). In fact, according to the Orchid Project, a London-based NGO, 77 per cent of female genital mutilation in Egypt is performed by those in the medical profession (Eltahawy, 2015, p. 125), and, in 2018, it was suggested that three out of four girls under the age of 14 are cut by trained medical professionals (Langer, 2018). Not only did the 1994 decree legitimise female genital mutilation, but it also did not reduce the number of casualties that came with the procedure. Deaths of girls being circumcised in private doctors' clinics were reported often and 11 deaths were officially recorded in one year (Al-Dawla, 2000, p. 431). The ban on medical practitioners performing the procedure was reiterated in 2008, after a twelve-year-old girl died from an anaesthetic overdose while undergoing the practice in Minya, in southern Egypt (Eltahawy, 2015, p. 122), but, again, this was widely ignored. In June 2013, thirteen-year-old Soheir el-Batea died in Daqahleya, northeast of Cairo, after a doctor had performed FGM on her at her family's request (Eltahawy, 2015, p. 123). The medical report attributed her death to an allergic reaction to penicillin. Both the doctor and Soheir's father stood trial in 2014, but both were acquitted of her death (Eltahawy, 2015, p. 123). Despite these 
deaths, many medical professionals do not see an issue with FGM, nor do they regard it as a risky procedure (Rasheed, et al., 2011). Of 271 nurses who took part in a study which took place between 2008 and 2010, 33.8 per cent of them had no information about the risks and did not believe that there were major medical implications as a result of it (Rasheed, et al., 2011).

The acceptance of FGM into the medical sphere legitimises the practice among the wider Egyptian population as it makes it appear to no longer be barbaric or unhygienic (Eltahawy, 2015, p. 126). Medicalised FGM has perpetuated the practice within the elite and privileged classes who were beginning to work to put an end to it. There are still many among the educated elite who are calling for the practice to be denounced, but their progress has been inhibited by those medical professionals who have been advocating for its continuation (Al-Dawla, 2000, p. 429). In some rural areas, the introduction of medicalisation was mostly ignored. Doctors were assigned to villages to perform the operation according to medical guidelines, which meant for many, the removal of only part of the clitoris, rather than the whole clitoris and the clitoral hood, which would have helped to slow the rates of both the second and third types of mutilation (Atiya, 1984, p. 139). However, these doctors were met with mistrust and any woman who chose to see them were viewed as weak by the rest of their communities (Atiya, 1984, p. 139) and, in the majority of cases, neither the families nor the girls ever consented to see these doctors (Atiya, 1984, p. 139). Despite low uptake of medical FGM in many rural areas, evidence suggests that the rate of medicalisation across the country has risen by 22 per cent in the past 20 years (Eltahawy, 2015, p. 125). Egypt is among some of the very few places in the world to have adopted female genital mutilation into their medical community (28toomany.org, 2019) and this top-down adoption of FGM is, undoubtedly, why it has continued there at such alarming rates.

\section{Their stories}

This practice has, up until this point, been addressed from an outsider perspective, but it is important to directly address what has been said of female genital mutilation by the victims who have been subjected to it. It appears that there is not a single woman who has forgotten their cutting and has not regarded it as a horrific act in their childhood, and not one of these young children gave consent to what they would be subjected to (Toubia, 2000, p. 426). Nayra Atiya's Khul-Khaal: five Egyptian women tell their stories and Nawal el Saadawi's The Hidden Face of Eve have included first-hand accounts of Egyptian women who have undergone FGM. There are many commonalities between the individual experiences of these women. Alice, an Egyptian Christian, and Suda, an Egyptian Muslim, both recall awaiting their fate in trepidation (Atiya, 1986, p. 41/ 79). Suda remembers crying for a week before her circumcision at age twelve, after knowing her time would be coming since she was eight years old (Atiya, 1984, p. 79). Om Gad, Suda, and the woman from el Saadawi's book have vivid memories of being held down by family members in an attempt to stop them struggling against the daya who was performing the procedure 
(Atiya, 1984, p.11/80. / el Saadawi, 2015, p. 70). From Nawal El Saadawi's account of her own mutilation, she recalls calling out for her mother for help, only to find her by her side (El Saadawi, 2015, p. 19). This experience is not uncommon and adds a layer of betrayal to the act. What is most common in all of the experiences is the excruciating pain that is felt either during the procedure or in the hours after when the effects of the anaesthetic, for those who were fortunate enough to be given any, wore off. For Om Naeema, who was treated by her grandfather who was a male nurse, she did not feel anything when she was cut as a result of the anaesthetic she was administered, but once the medicine faded, she recalled feeling as though 'the sky would come crashing down about [her] head from the pain' (Atiya, 1986, p. 138). Dunya, who was not given the luxury of numbing described the moment the knife hit being 'as if someone had built a fire under [her]' (Atiya, 1984, p. 109). Aside from the pain, some women are not guaranteed a swift procedure. Om Gad recalls her daughter's circumcision, in which the knife was blunt, and it took three attempts to completely sever the clitoris from her body (Atiya, 1984, p. 12). In the following days, girls are warned to not let their legs touch in case the wound completely heals up and they must be cut again. The pain continues for days and is sometimes so unbearable that some girls cannot face urinating (El Saadawi, 2015, p. 70) which results in a whole host of urological issues. From most accounts, the healing process takes around seven days (Atiya, 1986, p. 12) and on the seventh day, there are many different ways of celebrating the practice. According to Alice, the Christian celebration involves new dresses which the clitorises are tied to, and the young girls and their families parading through the streets until they reach the Nile, at which point they are to throw the clitorises into the river in order to bring them happiness (Atiya, 1984, p. 41). Suda remembers being given her severed part and being told to keep it with her for a month to prevent becoming sterile, in case someone put the evil eye on her (Atiya, 1984, p. 81). Om Gad, however, tells of a young woman who was subjected to the procedure one week before her wedding and the wedding night (Atiya, 1984, p. 12). Each individual story holds its own weight and tells of a different experience, but what is common throughout every account is the force used against these young girls and the excruciating pain they endure at the time of the incident, the days of recovery and healing directly after and through the rest of their lives.

\section{Attitudes towards continuation}

Given the accounts recorded above, it would be relatively safe to assume that many women would be opposed to continuing the practice. However, three of the five women from Atiya's book did go on to circumcise their daughters (Atiya, 1984, p. 11/51/79), as they believed they must carry on the tradition (Atiya, 1984 p. 11). Many people in villages apparently had no knowledge of the 2008 ban, with one 53-yearold survivor of FGM saying:

"Cutting happens whether it's against the law or not; it must be carried out because that's the way to maintain the purity of girls to make sure that the girl is not 
out of control. We don't care if it's against the law or if they're trying to stop it. We know doctors who are willing to continue and have done so." (Eltahawy, 2015, p. 124)

In addition to this, the woman's affairs advisor to Mohamed Morsi described FGM as 'beautification' and only objected to the practice when it was carried out on girls as young as seven and eight (Eltahawy, 2015, p. 128). She was not alone in this thought, as, according to a study released in 2010, 82 per cent of women supported the continuation of FGM (Dalal., et al. 2010). This is a 6 per cent decrease since the 1995 Egypt Demographic and Health Survey (DHS) found that 88 per cent of mothers who were asked whether they would circumcise their daughters reported that they would (El-Gibaly., et al. 2002), but it is still a remarkably high number. It is this insistence on the practice by mothers and grandmothers that perpetuates the issue so consistently and the fear that, without it, their daughters will become sexually promiscuous and out of control (Eltahawy, 2015, p. 118). Additionally, according to a study put forward by Langer, it is clear that men are also in favour of the continuation of FGM (Langer, 2018). As evidenced by fig. 1, men are considerably more supportive of the practice than women, and generally do not see the negative implications of the practice (Langer, 2018). This could be due to a lack of education on the issue but seems more to be as a result of traditional and religious beliefs (Langer, 2018).

There have been numerous campaigns and groups that have attempted to put an end to, or at least slow down the rates of female genital mutilation in Egypt such as the Egyptian Female Genital Mutilation Taskforce which is an umbrella coalition of about 70 organisations, founded in 1944 (Al-Dawla, 2000, p. 427). The members are from a wide range of backgrounds and are all active in the fields of development, women's rights, human rights, health, education and legal aid (Al-Dawla, 200o, p. 429). According to the Orchid Project, anti-FGM work began in Egypt in 1904, and according to a 2002 study, girls were then 10 per cent less likely to undergo the treatment than their mothers, and 14 per cent of circumcised girls thought it was unnecessary (El-Gibaly., et al. 2002). Additionally, girls who live in urban governorates and in urban areas of Lower Egypt are 31 per cent and 28 per cent less likely to be circumcised than those who live in rural Upper Egypt (El-Gibaly., et al. 2002). For those in the countryside, where FGM is more prevalent than in the cities, activists go door-to-door raising awareness of the dangers (Langer, 2018). There is also a childline protection hotline that neighbours or relatives can call to alert the authorities about a potential case of FGM, but police officers rarely respond (Langer, 2018). Another study which tracked the prevalence of support for FGM in 2005, 2008 and 2014 reiterated this decrease of support, from 62 per cent in favour in 2008 to 58 per cent in 2014 (Alkhalaileh, et al., 2018). While this is statistically a decline, it is still relatively slow progress, especially considering the fact that campaigning began 115 years ago to put an end to this harmful practice, and it is clear that, generally, most of the population are still in favour of the continuation of female genital mutilation. 
The Egyptian case is incredibly compelling as it justifies female genital mutilation by using both an excuse that is very common among many Muslim societies to justify the oppression and abuse of women, "honour", and in addition, legitimises FGM in its own individual way, with medicalisation. The combination of these two justifications manages to include both the more traditional and the more modern and 'Western' classes, as, even those who care little for honour and old traditions are given a reason to still continue to practice FGM due to the fact that it is advocated for by the medical community. Despite the evidence given by the women mentioned above about the terror and pain that this procedure puts them through, female genital mutilation has been consistently justified by many all across the country for a variety of reasons, and this is why it has continued to be so prevalent in Egyptian society.

Fig.1

Attitudes toward Female Genital Mutilation

Percentage of respondents who agreed or strongly agreed with selected statements about female circumcision, IMAGES MENA Egypt 2016

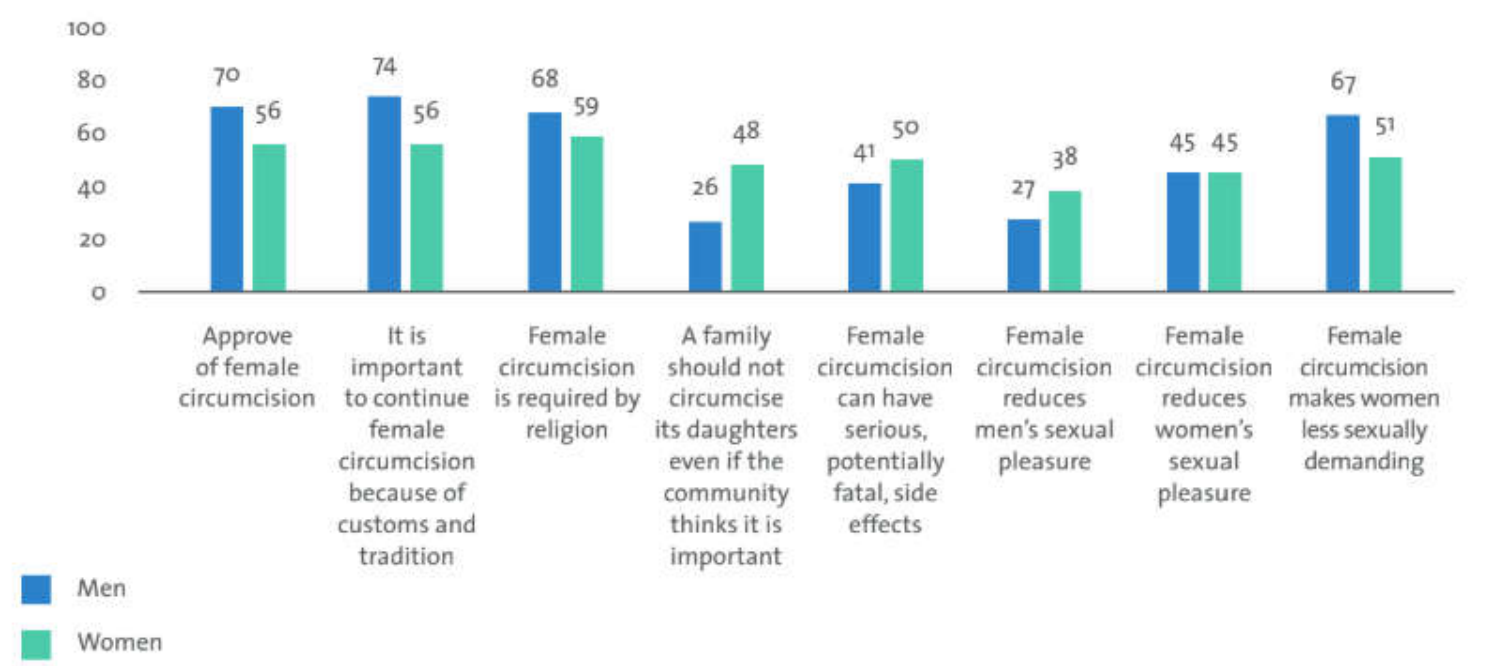

(UN Women, 2017, p. 78) 


\section{Conclusion}

In the words of the Hon. Mrs Justice Whipple, in her sentencing remarks of the 2019 U.K. conviction:

'Let's be clear: FGM is a form of child abuse. It involves deliberate physical mutilation.... It is an offence which targets women, typically being inflicted on women when they are young and vulnerable. It is often done with the collusion of family members. And then it is hidden.' (R v N, 2019, p. 2)

These remarks are entirely factual, and yet encompass the emotion entwined in this procedure. In the Egyptian case, it is clear that the taboo of female sexuality is the main reason for the continuation of female genital mutilation. While this may not necessarily be explicit, it is implied in the other justifications given for continuation. Citing Islam is the most common and popular explanation for the practice, despite the fact that there is no basis for the claims that Islam necessitates it. Not only is there no certifiable textual support for FGM, but many among the religious elite, including many from Al-Azhar have denounced the practice altogether. With the lack of this support, it is apparent that it is only interpretations of the Qur'an that understand the Sunnah of Yusuf to portray all women and female desire as evil and cunning that has condemned women to practices which control them, such as FGM. Islamic theories, such as Ghazalian theory, have perpetuated this and meant that this belief has become the mainstream and overshadowed the sex positivity of the Qur'an. Although the religious texts do not condone FGM, the theories and interpretations that surround them allow for the acceptance of practices such as these. As a result, this thought has perpetuated and enabled this control of female sexuality in many different ways and in many different countries. Egypt's adoption of this justification has led to issues with honour and the preservation of chastity, which has not only resulted in female genital mutilation but also 'virginity tests' and honour killings. While it is true that other predominantly Muslim countries do not practice this and without the ancient establishment of the procedure it may not have been so prevalent in Egypt, it is undeniable that the taboo of female sexuality in Islam has led to the continuation on the scale it is at today. Rates do appear to be slowing, and that is a considerable feat, but in the wake of the Arab Spring and the rise to power of conservative political parties such as the Muslim Brotherhood, it begs the question as to whether this momentary dip is sustainable. The next step from here is to establish a solution and a method of putting an end to the practice altogether. Is education on the medical implications enough to prevent the medical community from perpetuating this procedure? Or does there also need to be a re-education of the Islamic teachings of sex-positivity? There seems to be a need for education on the harm of female genital mutilation. The fact that medical professionals do not believe that there are any ramifications in the practice confirms this. While so many countries other than those in which medicalisation has occurred have proven that there are no medical benefits of FGM, external forces risk the same condemnation as the Egyptian activists. The fear of 
intervention and accusation had kept international criticism of FGM at bay. However, the UN has now adopted a zero-tolerance policy and is working towards putting an end to the practice worldwide (UN, 2019). Egyptian charities have begun the process of teaching about the impact of FGM, but for the extent of the problem in Egypt, it seems that there needs to be a regional effort to ensure this is possible. The dangers must be taught in medical schools and information must be made more readily available.

Recognising that the taboo of female sexuality is at the heart of the justification for the continuation of FGM in Egypt is only the starting point in trying to establish how to put an end to it. This taboo has led to the unlawful and horrific treatment of so many women across the Middle East, and the next step is attempting to re-educate and reassess Islam and the interpretations around the Qur'an, hadith and the Sunnah to ensure that this and other harmful practices are brought to an end.

\section{Glossary}

- Daya: traditional Egyptian midwives and birth attendants who also perform defloration and female circumcision. (Langer, n.d.)

- Fatwa: an Islamic legal pronouncement, issued by an expert in religious law. (Kibbani, n.d.)

- Fitna: has a variety of different meanings mostly referring to a feeling of disorder or unrest, but also attractiveness or captivation. (Huda, 2018)

- Fitrah: the belief that all humans are born with a love of Allah in a state of purity and innocence. (Anon., n.d.)

- Hadith: a collection of traditions containing sayings of the prophet Mohammed, with accounts of his daily practice which constitute the major source of guidance for Muslims apart from the Qur'an. (Anon., 2019)

- Makrama: an Islamic term referring to noble, but not necessary actions. (Sheikh, 2018)

- Mustahab: an Islamic term referring to recommended, favoured or virtuous actions. (Dikmen, n.d.)

- Nafs: the soul, psyche, ego, self, life, person, heart or mind. (al-Akiti, 1997)

- Qiyas: the principle of analogy applied in the interpretation of points of Islamic law not clearly covered in the Qur'an or Sunnah through use of analogical inference or deduction. (Anon., 2019)

- Sunnah: the body of traditional social and legal custom and practice of the Islamic community and is a major source of Islamic law alongside the Qur'an and the Hadith. (Afsaruddin, 2019)

- Wasa'il hadith: a reputable book of hadith in Shia Islam. (Tirkalai, 2015) 
Tabi Stew

Is the Taboo the Female Sexuality......

\section{Bibliography}

Afsaruddin, A., 2019. Sunnah. [Online] Available at: https://www.britannica.com/topic/Sunnah [Accessed 12 April 2019].

al-Akiti, M. A., 1997. The Meaning of Nafs. [Online] Available at: https://www.livingislam.org/nafs.html [Accessed 12 April 2019].

Anon., 2019. Merriam-Webster. [Online] Available at: https://www.merriamwebster.com/dictionary/hadith [Accessed 12 April 2019].

Anon., 2019. Merriam-Webster. [Online] Available at: https://www.merriamwebster.com/dictionary/qiyas [Accessed 12 April 2019].

Anon., n.d. Wikipedia. [Online] Available at: https://en.wikipedia.org/wiki/Fitra [Accessed 12 April 2019]

Al-Dawla, A. S., 20oo. The Story of the FGM Taskforce: an ongoing campaign against female genital mutilation. In: P. Ilkkaracan, ed. Women and Sexuality in Muslim societies. Istanbul: Women for women's rights (WWHR)/Kadmin Insan Haklari Projesi (KIHP), pp. 427-433.

Alkhalalileh, D., Hayford, S. R., Norris, A. H. \& Gallo, M. F., 2018. Prevalence and attitudes on female genital mutilation/cutting in Egypt since criminalisation in 2008. Culture, Health and Sexuality, 20(2).

Atiya, N., 1984. Khul-Khaal: Five Egyptian women tell their stories. Cairo: The American University in Cairo Press.

Dalal, K., Lawoko, S. \& Jansson, B., 2010. Women's attitudes towards discontinuation of female genital mutilation in Egypt. Journal of injury and violence research.

Daly, M., 1991. Chapter five: African Genital Mutilation: The Unspeakable Atrocities. In: Gyn/Ecology: The Metaethics of Radical Feminism . London: The Women's Press Ltd. , pp. 153-177.

Doumato, E., 2010. Saudi Arabia. In: S. Kelly \& J. Breslin, eds. Women's Rights in the Middle East and North Africa: Progress amid resistance. New York: Freedom House, pp. 1-25.

El-Gibaly, O., Ibrahim, B., Mensch, B. S. \& Clark, W. H., 2002. The decline of female circumcision in Egypt: evidence and interpretation. Social Science and Medicine, 54(2), pp. 202-220.

El Saadawi, N., 2015. The Hidden Face of Eve. London: Zed Books Ltd.

Eltahawy, M., 2015. Headscarves and hymens; why the Middle East needs a sexual revolution. New York: Farrar, Straus and Giroux. 
Holland, K. 2018. Menstruation: Facts, Statistics and You. [Online] Available at: https://www.healthline.com/health/facts-statistics-menstruation\#1 [Accessed 23 April 2019].

Huda, 2018. The Meaning of the Term 'Fitna' in Islam. [Online] Available at: https://www.thoughtco.com/the-meaning-of-fitna-in-islam-2004280 [Accessed 12 April 2019].

J., W., Ayonrinde, O. \& Maingay, S., 2010. Female genital mutilation: Cultural and psychological implications. Sexual and Relationship Therapy. pp. 161-169.

Kibbani, S. M. H., n.d. The Islamic Supreme Council. [Online] Available at: http://www.islamicsupremecouncil.org/understanding-islam/legalrulings/44-what-is-a-fatwa.html [Accessed 12 April 2019].

King, H., 2015. The rise and fall of FGM in Victorian London. [Online] Available at: https://theconversation.com/the-rise-and-fall-of-fgm-in-victorian-london38327

Knight, M., 2001. Curing Cut or Ritual Mutilation?: Some Remarks on the Practice of Female and Male Circumcision in Graeco-Roman Egypt'. Isis, pp. 317-338.

Lamrabet, A., 2018. Women in the Qur'an: an emancipatory reading. Markfield: Square View.

Langer, A., 2018, Women in Egypt: Harassed, Mutilated and Disenfranchised. [Online]Available at: https://www.spiegel.de/international/tomorrow/genital-mutilation-inegypt-stop-taking-your-daughters-to-be-mutilated-a-1199322.html [Accessed 12 April 2019].

Lesclingand, A. A. G. M. R. P., 2016. Female genital mutilation, Overview and current knowledge. Population, pp. 217-296.

Lorenzi, R., 2012. How Did Female Genital Mutilation Begin? [Online] Available at: https://www.google.co.uk/amp/s/www.seeker.com/amphtml/how-didfemale-genital-mutilation-begin-1766105357.html [Accessed: 24 April 2019]

Madsen, P., 2015. 12 Crazy Amazing Facts About the Clitoris. [Online] Available at: https://www.huffingtonpost.com/pamela-madsen/12-crazy-amazing-factsabout-the clitoris_b_7501188.html?guccounter=1\&guce_referrer_us=aHRocHM6Ly93d3 cuZ29vZ2xlLmNvbS8\&guce_referrer_cs=8gtGuW4vb_wAQ6ZK4Kj8Qg [Accessed 4 March 2019]

Mahmoud, M. I. H., 2016. Effect of female genital mutilation on female sexual function, Alexandria, Egypt. Alexandria Journal of Medicine.

Mernissi, F., 2011. Beyond the veil: Male-Female Dynamics in Muslim Society. London: Saqi Essentials. 
Munir, M., 2014. Dissecting the claims of legitimisation for the ritual of female circumcision or female genital mutilation (FGM). [Online] Available at: http://www.qscience.com/doi/10.5339/irl.2014.6 [Accessed 22 March 2019].

Okwubanego, J. T., 1999. Female circumcision and the girl child in Africa and the Middle East: The eyes of the world are blind to the conquered. Male/female circumcision in the Middle East, pp. 159-187.

Price, M., 2019. Can one conviction end FGM in the UK?. London: BBC Sounds.

Rasheed, S. M., Abd-Elahi, A. H. \& Yousef, F. M., 2011. Female genital mutilation in Upper Egypt in the new millenium. International Journal of Gynaecology $\mathcal{E}$ Obstetrics, 114(1), pp. 47-50.

R v N [2019] CCC 1 https://www.judiciary.uk/wp-content/uploads/2019/o3/r-v-nfemale-genital-mutilation-sentencing-remarks-whipple-j.pdf [Accessed: 24 April 2019]

Sheikh, M., 2018. Legal norms. ARAB2280 Islamic Law: Theory and Practice. 17 April, University of Leeds

Tirkalai, H. R., 2015. The Manhaj of Figh-Ul-Hadith by Shaykh Hurr Ameli on the basis of Wasael ush-Shia. [Online] Available at: https://www. scipress. com/ILSHS.6o.49.pdf [Accessed 12 April 2019].

Toubia, N., 200o. What is Female Genital Mutilation . In: Women and Sexuality in Muslim Societies. Istanbul : Women for Women's Human Rights (WWHR)/Kadmin Insan Haklari Projesi (KIHP), pp. 417-426.

U.N., 2019. International Day of Zero Tolerance for Female Genital Mutilation, 6 February. [Online] Available at: https://www.un.org/en/events/femalegenitalmutilationday/ [Accessed 20 April 2019].

U.N. Women, 2017. Understanding Masculinities: Results from the international men and gender equality survey (images) - Middle East and North Africa. [Online]Available at: https://promundoglobal.org/resources/understandingmasculinities-results-international-men-gender-equality-survey-imagesmiddle-east-north-africa/?lang=english [Accessed 11 April 2019].

Wasael ush-Shia. [Online] Available at: https://www.scipress.com/ILSHS.6o.49.pdf [Accessed 12 April 2019].

WHO, 2019. Male circumcision for HIV prevention. [Online] Available at: https://www.who.int/hiv/topics/malecircumcision/en/ [Accessed 19 April 2019].

28toomany.org Medicalisation of FGM: A growing problem [Online] Available at: https://www.28toomany.org/thematic/medicalisation/ [Accessed 22 April 2019]. 